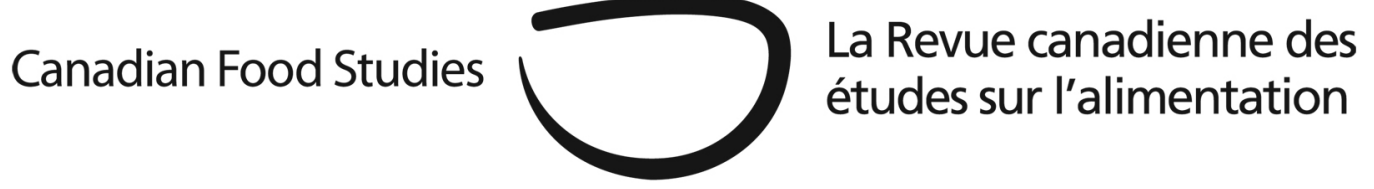

Book Review

\title{
How Canadians Communicate VI: Food Promotion, Consumption, and Controversy
}

Charlene Elliott (Ed.)

University of Athabasca Press, 2016, 380 pages

Reviewed by Kathy Dobson, Fleur Esteron, Irena Knezevic, Agnes Malkinson, Scott Mitchell, Andrea Noriega, Chloe Poitevin DesRivieres, Julie Pasho, and Antonella Pucci (Carleton University)

Elliott's collection brings communication studies to the core of food studies, and this makes it a long-overdue book. While not all authors are communication scholars, the range of topics covered in the book are representative of how enmeshed the study of food and the study of human communication are. The title of the book alludes to a Canadian focus and many of the contributions deal with Canadian identities in relation to food. The subtitle, Food Promotion, Consumption, and Controversy, prepares the reader for the collection that largely deals with issues around consumption of food and food media, and its place in the economic system that underpins it. Though the quality of its seventeen chapters is somewhat uneven-with some appearing undercooked, and others baked to perfection — the collection as a whole makes for an interesting read.

\section{Chapter 1, “Communicating Food Quality” by Charlene Elliott and Wayne McCready,} offers appetizing ideas about how place of origin is deployed as a marketing strategy to promote quality goods. The authors depict product placement as a mechanism to communicate a sense of distinction and superiority in high-end foods. Elliott and McCready successfully build on this argument by unveiling how food and place form a co-constitutive union. That said, food and its 
processes are emplaced in a network of histories, social relations, nostalgia, sensory experience, and the imaginary. This chapter brings place studies into a savory but critical conversation about food marketing. It prompts the reader to consider the potential implications, but does so indirectly. If place is so powerful a communication tool in the marketing of prestige foods in terms of suggesting quality of ingredients, process, and nutrition, are these implicit claims always valid or truthful? What are some of the criticisms levied against geographic-certification organizations regarding the oversight, admittance and practices of their members? Still, this essay provides thoughtful explorations of the intertwining ways food and place engage readers with contingent examples of how place and its associated values interact with quality of food.

In Chapter 2, “The Food Retail Environment in Canada” Jordan LeBel demystifies the means by which food appears on the shelves of our grocery stores, and subsequently, on our plates. The essay provides valuable insight into how the retail food sector operates, the power it exerts within the Canadian food industry, as well as the choices that consumers make in the grocery aisles. LeBel draws out some of the challenges that retail food spaces face with changing consumer demands and increasingly aggressive competitors. This essay plainly illustrates the ways in which grocery store shelves are stocked, such as who makes decisions about what is available to consumers, what retail motivations are put forth, and to what extent marketing tactics are deployed. While LeBel makes a powerful argument about the need to expand the ways in which we talk about food, he fails to mention consumer skepticism of marketing messages by simply presenting consumers as complacent and susceptible to manipulation. A brief discussion on how consumers can exercise their power in making food choices would have been beneficial.

\section{Chapter 3, "Selling Nutrition: Current Directions in Food Fortification and Nutrition- Related Marketing” by Valerie Tarasuk, is a compelling case for the limitations consumers} face in making informed decisions about healthy eating. There are, the author argues, several factors involved in hindering consumers' potential to make healthy food choices. The main factor is that food manufacturers obscure nutrition information through the messaging, marketing, and front-of-package labelling they use in order to make their products more appealing to consumers. Another important factor is that consumers are not necessarily knowledgeable about what nutrients they need, in spite of the widespread availability of population-level information on nutrient requirements for Canadians. The shifting landscape of food policy, paired with outdated information for nutrition labels, has made it very challenging for consumers to appropriately assess their nutrient needs. Tarasuk convincingly suggests that the answer to making healthier food choices may not be more education, but a reform of nutrition labelling.

Eric Pateman and Shannon King offer a taste of Canadian culinary tourism in Chapter 4, "Edible Canada-The Growth of Culinary Tourism". They chart the growth of the culinary tourism industry in Canada by focusing on companies like Vancouver-based Edible Canada, 
which not only welcomes tourists and locals to taste food, but also delves into a deeper understanding of the food's regional context. While the chapter effectively explains the typical Canadiana experience of culinary tourism, such as exploring fresh lobster on the east coast, red meat in Alberta and local wines in the BC and Ontario regions, the authors fail to draw attention to Canada's diverse, diasporic nature - in particular, how immigrants and their descendants have created dishes inspired by their home countries that come to embody the new regions they inhabit. Aside from traditional regionalism that misses the diasporic diversity of Canadian food, Pateman and King make utopic arguments of how culinary tourism traces the food back to its roots, by providing stories about how the food is produced in local farmer's markets and bakeries. Nevertheless, their chapter fails to interrogate culinary tourism as another fetishized tool used to incite consumers to buy into particular notions of “authenticity”.

\section{In Chapter 5, “La cuisinière canadienne: The Cookbook as Communication”, Ken Albala} demonstrates how cookbooks do more than just teach consumers how to cook recipes; they are embedded with different cultural narratives that "implicitly promise a better life”. Albala contends that cookbooks are used to empower individuals to embrace their identity and their heritage. From healthy living cookbooks embracing weight loss and conscious eating, to cookbooks containing traditional recipes once eaten by ancestors, these culinary texts weave in diverse narratives. In relation to the latter, Albala serves up a glimpse of how La cuisinière canadienne (Canada's first written and published culinary text in 1840) reveals unique and traditional Montreal dishes and techniques that date back to before colonial settlement. The recipes provided within La cuisinière canadienne function as a way of preserving the culture of a French-speaking population against a dominant English culture. By deconstructing La cuisinière canadienne, Albala dishes an insightful take on how cookbooks can be used as a form of communication, which romanticises a culture through food as a way to maintain a sense of identity.

\section{Chapter 6, “The Dinner Party: Reworking Tradition Through Contemporary} Performance” by Jacqueline Botterill, provides social and cultural insights into the traditional and contemporary dinner party. Botterill explains that historically, British and French bourgeoisie's social position was communicated through curation of the dinner party. Honourable guests were invited and strategically seated, elaborate floral settings that complemented the table décor were deliberately arranged, and the dinner party moved throughout the home to showcase well-decorated rooms. Botterill proposes that the contemporary dinner party shows little resemblance to its traditional counterpart. Perhaps most interestingly, the contemporary party differs due to its use of the Internet: invitations are sent on Facebook, and recipes selected from websites. After the dinner party, photos are shared on social media in hopes of virtually continuing that evening's festivities. Botterill insightfully illustrates that in both traditional and contemporary dinner parties, food is secondary. Ultimately, this 
chapter demonstrates that while the dinner party's function has evolved over time, its performance is indeed a hallmark of its time period.

"Why do audiences listen to radio programs showcasing conversations about food and eating, and how has food radio nourished Canadian listeners?” asks Nathalie Cooke in Chapter 7, “Canadian Food Radio”. Regardless of its inability to provide the complete sensory experience of eating, the continued competition from American broadcasters, and the rise of multi-sensory television programming, food programming on the Canadian radio maintained its appeal throughout the twentieth century. Cooke reveals that the history of food radio programming and the history of women in Canadian broadcasting have been intertwined, with food programs having always been a mix of entertainment, education and product marketing. Key Canadian women broadcasters maintained authoritative status as they dispensed advice to homemakers, ensuring their programs were perceived as largely educational. Moreover, these broadcasters paid close attention to the diversity of regional cuisines in Canada, playing no small role in defining the culinary Canadian identity. The chapter, however, does not deliver clear answers to its opening questions. Instead, it feels somewhat like a visit to a museum, where the readers can find a bounty of artifacts from which to assemble their own answers.

From frosting and baking, to performed domesticity and hyper-masculinity, “Of Men and Cupcakes: Baking Identities on Food Network” by Irina Milhalache (Chapter 8) broadens the educational consideration of cooking shows. The content of Food Network shows-including who is cooking, how they are cooking, and what they are cooking-is culturally significant. The object of her inquiry is the cupcake, which Milhalache traces as a site through which chef identities are inscribed on food network shows. The cupcake represents an object that complicates the performance of gender. The chef's identity becomes fluid-just as fluid as the ingredients that can be mixed in and taken out of cupcake recipes. While Food Network shows may be less instructive and more entertaining, they are nonetheless learning experiences. The viewers are able to reflect on their own identity through the performance of the televised chef. Through sound argument and clear comprehension of Judith Butler's “gender performance”, the author compels us to rethink the way we look at the cupcake. The cupcake itself invites playfulness for both the baker and the viewer, one in which the cupcake can be appropriated to comply to the performance of a "masculine" or "feminine” identity; and sometimes somewhere in between.

In Chapter 9, “Snapshots of a Canadian Cuisine”, Elizabeth Baird begins to answer the long-standing question of 'What is Canadian food really?' For Baird, it is four things: regional ingredients, distinctive cooking techniques, codification through cookbooks and 'heroes', and iconic dishes. As editor of Canadian Living from 1987-2009, Baird herself is one of these Canadian 'heroes'. She truly gives the reader "snapshots” of Canadian cuisines past, while guiding the reader to the present of Canadian food identity. Baird makes it clear that the nation's cuisine has particular distinctive qualities, and that some are so obvious that we hardly consider 
their importance-we rarely think about baking, barbequing, and canning as "Canadian”, but these have been major sites giving shape to our food identity and ingenuity. Baird invites the reader to contemplate the future of Canadian cuisine within the new media landscape of food bloggers and Canadian celebrity chefs.

Chapter 10, or John Gilchrist’s “Everybody's a Critic: A memoir” presents an interesting listicle of the things he has learned over nearly four decades as a seasoned food critic. His tenure and multi-media experience as a food critic provides a refreshing narrative to a business that is fast becoming the territory of the every-woman/man. His essay contemplates both the history of Canadian food reviewing, and the democratizing effect of digital media on reviewing, which is increasingly making critical reviewers like himself irrelevant. Gilchrist equates the traditional way of restaurant reviewing with integrity. Although he does not explicitly criticize Facebook, Twitter, or blogs (and curiously neglects to mention other important digital food reviewer platforms, like Instagram and Yelp), he nonetheless implies that a certain kind of integrity has been lost. Gilchrist primarily reflects on the shift in food criticism; however, his references to Canadian celebrity chefs and their use of digital media platforms are particularly fascinating, and worth exploring for future research—as Baird signals, these culinary heroes shape Canadian food identities.

\section{Catherine Carstairs, Paige Schell, and Sheilagh Quaile's “Making the 'Perfect Food' Safe:} The Milk Pasteurization Debate" (Chapter 11) is an excellent overview of the history of milk pasteurization. The authors effectively chart the tensions between regulators and the medical community, who touted pasteurization as a crucial and necessary step for making milk products "safe", and the opposition from small dairy farmers who were pushed out of business by industrial-scale operations. The chapter presents the compelling argument that the mandatory pasteurization of milk happened not because of real health safety concerns, but rather as the result of a carefully crafted industry push to make consumers afraid of raw milk. In enforcing the mandatory pasteurization of milk, the government grants advantage to larger processors, since many small dairy operations are unable to afford the extra expense of pasteurization equipment. The chapter concludes that despite a recent interest in raw milk, and raw food more generally, this longstanding regulation is unlikely to change because of established "industrialized food systems”. Without making explicit claims, the authors do seem to suggest that this system inherently and consistently favours the processors over the consumers.

\section{Chapter 12, “Kraft Dinner ${ }^{\circledR}$ Unboxed: Rethinking Food Insecurity and Food” by Melanie Rock eloquently highlights a fundamental flaw in Canadians’ charitable donations. Although well-intentioned, Canadians who donate Kraft Dinner ${ }^{\circledR}$ to food banks exacerbate the problems of our current (and broken) food system. The case study is an example of the 'Band-Aid solutions' that characterize the food bank system. Preparing Kraft Dinner ${ }^{\circledR}$ requires milk, and margarine or butter, as indicated by box instructions, yet low-income recipients of donations are often unable}


to afford these dairy products. In fact, this product is a metaphor for the food bank system. Kraft Dinner® is palatable, but becomes a bitter disappointment to those who cannot afford dairy products. They are forced to eat something many would not consider "food”, thus further dehumanizing their food bank experience. Kraft Dinner® is cheap. The physical act of donating and receiving Kraft Dinner ${ }^{\circledR}$ further excludes an already socially marginalized populationrestating that they do not have the same privileges and rights as others. Although wellintentioned, the act of donating to the food bank further embodies the social and structural inequities faced by low-income populations.

\section{In, Chapter 13, "Hipster Hunters and the Discursive Politics of Food Hunting in Canada",} Rebecca Carruthers Den Hoed assesses the "hipster”, and "utilitarian” (typically lower class and/or Aboriginal) hunter. The hipster hunter is set apart from the utilitarian hunter, as an elite group claiming to have found the "right" way or correct attitude towards hunting. The hipster hunter could help revive hunting across Canada by making it appeal to those who need to see hunting as something genteel or noble, and wild meat as more gourmet. But, by appealing to elite food tastes, this also creates a deepening of class division. The visibility of the hipster hunter becomes problematic, as the authors outline, as it buries the ongoing conflicts surrounding Aboriginal discourses of hunting and hunting rights. On one hand, the author is critical of food researchers and practitioners for their exclusionary focus on agricultural foods, and on the other, she critiques the ways in which certain hunter discourses overshadow Aboriginal peoples' decades of struggle. The resulting arguments are somewhat unfocussed and less than convincing. However, the chapter offers a compelling and effective examination of the tendency for research and discourse around hunting to stigmatize or overlook certain communities and practices.

Pierre Desrochers' Chapter 14, “Lies, Damned Lies and Locavorism”, attempts to crumble the prevailing local food movement discourse. He asserts that food systems operate optimally and efficiently at a global scale due to unsuitable food production landscapes, dominant economic structures, and continual technological advancement in food production. He rejects the notion of "local" as socially just, economically and environmentally sustainable, and automatically promoting food safety and food justice. His critiques of the local food movement raise relevant issues regarding the effectiveness of localization as a means to create systemic and sustainable changes in the food system, even though the type of localization Desrochers describes (defensive localism) is an outdated viewpoint; local food scholars and advocates have long moved beyond this as they seek more reflexive and holistic strategies. By raising issues with locavore discourses, Desrochers attempts to refute the idea that the conventional food system is in need of systemic changes, and instead proposes solutions based on trade liberalization, technological advancements, and corporatization-the very "solutions" that ultimately led to the current unsustainable and unjust food system that locavores seek to change. 


\section{In Chapter 15, “Communication, Crisis, and Contaminated Meat: A Tale of Two Food} Scares”, Charlene Elliott and Josh Greenberg frame the perceived hazards of food poisoning as an area of public concern similar to growing fears around disease epidemics and terrorist attacks. Just as many scholars and commentators have ascribed fears and anxiety concerning these two major issues to sensationalized media coverage, the authors contend that part of the blame for the attention and worry around foodborne illnesses falls on the plate of the press. This chapter focuses on describing the political and economic fallout of various companies and agencies when there is a high-profile foodborne disease outbreak. Although the essay seems primarily concerned with the practices of news media in the beginning, there is little attention given to the signs and symbols present in news coverage of the two outbreaks described, despite the earlier discussion of their importance in shaping public understandings. Nonetheless, the authors' comparison of the Maple Leaf Foods and XL Foods incidents is an effective, wellwritten case study for understanding the how the risks that alarm people differ from the actual risks that may harm them, with communication strategies largely responsible for the differential perception of risk.

\section{Stephen Kline’s Chpater 16, “Canaries in the Supermarket: Moral Panic, Food Marketing and Children's Eating”, examines globesity—or the so-called obesity epidemic—paying particular attention to the moral panic surrounding childhood obesity. Similar to Elliot and Greenberg's discussion of the Maple Leaf Foods and XL Foods incidents, this chapter is concerned with food risk and communication. Kline attempts to survey and connect the dots between a range of issues, from the 'medicalization of the adipose child's body', to moral panic about children's weight gain through inaccurate or misleading reporting, risk perception, blaming advertisers for indoctrinating children into unhealthy diets, and finally the effects of changing patterns of domestic life on eating behaviours. Although these are all doubtlessly connected-as Kline manages to demonstrate throughout the chapter - the sheer scope of this argument means that some aspects (such as risk perception) are not as fleshed out as others, and the chapter loses a bit of focus as a result. This is especially evident towards the end, when there is a shift towards a sociocultural analysis of contemporary lifestyle practices, family dynamics, and changing norms and behaviour regarding food consumption.}

\section{Chapter 17, “'Death on a Plate': Communicating Food Fears in Modern North America”} by Harvey Levenstein, is an examination of fear and science communication, demonstrating how campaigns by food producers and sensationalized or misleading coverage by the media led to, for example, support for certain food regulations and the success of vitamin-enriched products. The main argument is that communications - through advertising and news media hype-both produce and "resolve" anxieties concerning food. Levenstein characterizes these as largely "technology-based fears" that are the result of a widening gap between food producers and consumers, a natural outcome of large-scale industrialization. Further, the discovery of vitamins and the germ theory of disease both served to move food choice beyond the realm of 
taste and everyday experience, and into unfamiliar territory that requires expert opinion and government intervention to navigate. Levenstein effectively unpacks how the actions of food producers, government regulators, and journalists paradoxically create fears about the dangers of mass produced food, and assuage anxieties through the introduction of standardized inspections and safety guarantees.

In conclusion, How Canadians Communicate VI: Food Promotion, Consumption, and

Controversy assembles a diverse range of material and voices at the intersection of food and communication, from advertising and promotion to journalism and policy. Some of the chapters are not as strong as the others, in some cases struggling to present focused, cohesive arguments, yet overall this is a strong volume that gives readers a broad tour through some of the most relevant issues at the intersection of communication and food. Despite the volume being somewhat uneven, many of the chapters connect to one another through various themes, arguments, or schools of thought, providing an altogether comprehensive account for anybody interested in communication practices and food systems. Readers will also be interested to know that the entire volume is available as a free pdf download from the University of Athabasca Press website. 